The third section deals with the isolation and characterisation of repair deficient mutants in Drosophila (Smith et al), the effect of meiotic and repair mutants on chromosome behaviour (Baker et al), the biochemistry of some repair mutants (Boyd et al), and the induction of mutations in repair mutants (Würgler and Graf). All this is summarised and put into perspective by Green.

Section IV, presumably the most relevant to the readers of the Journal of Medical Genetics, comprises eight contributions plus a summary chapter by Wolff. The section begins with a discussion of the role of DNA lesions and their repair in the production of chromosomal aberrations (Bender), followed by one on the relationship between DNA repair, chromosomal aberrations, and the potentially lethal damage caused by $x$-rays (Fornace $e t a l$ ). Further discussion of DNA repair in relation to chromosome aberrations (including the production of sister chromatid exchanges) is provided by Sasaki, while McCormick and Maher report on the repair systems which modify the yield of mutations in human cells in culture. Trosko et al then describe attempts both to use resistance to diptheria toxin as a marker for mutagenesis in cultured mammalian cells and to isolate DNA repair deficient Chinese hamster cell lines. This is followed by three brief reports: one on induction of mutation by ultraviolet radiations (UVR) in a UVR sensitive variant of the L5178Y mouse lymphoma cell line (Sato), one on the DNA replication and pyrimidine dimer excision in human fibroblasts receiving single or split doses of UVR (Waters), and one on the inhibition by aphidicolin of the DNA synthesis of isolated nuclei (Bertazzoni et al).

The section on mouse germ cells contains papers on the unscheduled DNA synthesis of male (Sega) and female (Pedersen and Brandriff) germ cells. Generoso reports on the effect of repair processes, in the fertilised eggs, on the yield of dominant lethal mutations and chromosome translocations induced by exposure of male postmeiotic germ cells to chemical mutagens, and Russel contributes the summary paper. The final section comprises a chapter by German on the human chromosomal instability syndromes and a brief note by Langley on DNA repair and assessment of risks to the human population.

This volume covers a lot of ground and cannot be expected to do it systematically. However, the $\frac{\mathbb{Q}}{\overparen{D}}$ editors have paid much attention to the arrangement of its material and the summary chapters provide $\overrightarrow{\vec{F}}$ continuity. These chapters, together with the general reviews, should be very useful to the non-specialist, while the other contributions present a good spectrum of current trends in DNA repair and mutagenesis in eukaryotes.

F B Giannelli

\section{Genetics: Human Aspects}

By A P Mange and E J Mange. ( $P p x+675$; figures + tables.) Philadelphia: Saunders College, Holt, $\vec{\oplus}$ Rinehart and Winston. 1980.

Contrary to the impression given by the title, the authors of this book aim to provide a comprehensive $\stackrel{\circ}{5}$ textbook of human genetics. It is well bound and printed and is written in a clear attractive style, $\overleftarrow{c}$ being punctuated by numerous line drawings of high $\vec{D}$ quality. The book is open to three criticisms. The $\vec{\bullet}$ authors expect very little of the reader's previous knowledge, even to the extent of providing appendices on basic algebra and organic chemistry, making the book much longer and hence more expensive. Secondly, the lack of medical background in the authors is evident in those sections devoted to clinical subjects. There is less depth and a considerable number of errors or omissions. It is suggested, for instance, that congenital adrenal hyperplasia results from defects in the biosynthesis of testosterone by the testes, the adrenal glands, or both, and that males with adrenogenital syndrome usually have ambiguous genitalia.

The third and most important criticism is that the book falls between stools in the British market. As a reference textbook it cannot compete with Vogel and Motulsky and yet is too long and expensive to recommend to students, particularly in medicine. It is of potential value to the medical practitioner who wishes to expand a knowledge of basic human genetics. The clear illustrations and problem lists with each chapter may prove useful to the geneticist responsible for student lectures, and on this basis it is worth adding to the collection of genetic departments. 